\title{
Heightened bronchial hyperresponsiveness in the absence of heightened atopy in children with current wheezing and low income status
}

\author{
J Mallol, J A Castro-Rodriguez, E Cortez, V Aguirre, P Aguilar, L Barrueto
}

Department of Paediatric Respiratory Medicine, Hospital CRS El Pino, University of Santiago de Chile (USACH), Santiago, Chile

Correspondence to: Professor J Mallol, Department of Paediatric Respiratory Medicine, Hospital El Pino, Ave Los Morros 13560, Santiago, Chile; jmallol@vtr.net

Received 28 March 2006 Accepted 26 August 2007 Published Online First 27 September 2007

\begin{abstract}
Background: Although global studies such as the International Study of Asthma and Allergies in Childhood (ISAAC) have provided valuable data on the prevalence of asthma in children in Latin America, there is little information on the relationship between asthma symptoms, pulmonary function, bronchial hyperresponsiveness (BHR) and atopy in the region.
\end{abstract}

Methods: This study examined the relationship between self-reported wheezing in the past 12 months, pulmonary function, airway responsiveness and atopy in children from a low income population in a neighbourhood of Santiago, Chile. Two random samples (100 each) of children aged 13-14 years who participated in ISAAC phase I were selected according to whether or not they reported wheezing in the past 12 months. Spirometry, the methacholine bronchial challenge test and the prick test were performed in all individuals.

Results: Children who reported current wheezing had significantly higher BHR to methacholine compared with those without wheezing $(71.6 \%$ vs $52.6 \% ; p=0.007)$ and no significant difference was found in forced expiratory volume in $1 \mathrm{~s}(116.7(12.3) \%$ vs $120.3(14.5 \%)$;

$p=0.11)$. The prevalence of atopy was not significantly different between those children who reported wheezing compared with those who did not $(44.2 \%$ vs $42.3 \%$; $p=0.89$ ). Multiple regression analysis showed that only BHR to methacholine (OR 2.72, 95\% Cl 1.25 to 4.13; $\mathrm{p}=0.01$ ) and maternal asthma (OR $3.1,95 \% \mathrm{Cl} 1.2$ to 8.3, $p=0.03$ ) were significant risk factors for current wheezing.

Conclusions: Our results support previous findings suggesting that in adolescents from underprivileged populations, self-reported current wheezing is related to BHR but not to atopy.

The largest global epidemiological study (International Study of Asthma and Allergies in Childhood (ISAAC)), which includes the main regions of the world and countries with different levels of development, provided important worldwide comparative information on the prevalence of asthma symptoms in childhood. In developing regions such as Latin America, this study has provided information on the prevalence of asthma, revealing that apart from a wide variability in the prevalence of self-reported asthma symptoms, some of its centres were within those with the highest prevalence of asthma in the world. ${ }^{1}$ It has been demonstrated that the prevalence of asthma symptoms, bronchial hyperresponsiveness (BHR) and atopy varies greatly between and within countries, independent of their development status and other cultural characteristics, such as language. ${ }^{12}$ Although the reasons for these findings are unknown, it is likely that distinct environmental factors acting at different localities could play an important role on the observed variability. BHR is considered an important feature of asthma, representing a valuable objective measure for epidemiological studies on the disease. Atopy, indicated by skin reactivity to common allergens, is related to the development, prevalence, persistence and severity of asthma symptoms and is also closely associated with BHR in asthmatic patients and in random samples from the general population. ${ }^{3-6}$ In asthmatic children from developed countries, the relationship between asthma related symptoms, lung function, BHR and atopy has been evaluated $^{7-10}$ and the findings of some population based studies have shown an association between symptoms, atopy and BHR. ${ }^{11}{ }^{12}$ However, there is some controversy with respect to whether the deterioration in lung function and increased BHR in children with asthma symptoms are related to atopy $^{7-12}$ and doubts have been cast on the causal role of atopy in asthma. ${ }^{13}{ }^{14}$ For example, Pearce and colleagues, ${ }^{14}$ analysing nine population based surveys, showed that the prevalence of atopy (positive skin test) in asthmatic children from developed countries ranged from $40 \%$ to $79 \%$, and less than $50 \%$ of asthma cases were attributable to atopy. Moreover, a large survey ${ }^{15}$ carried out in the UK in adolescents and young adults demonstrated that the proportion of current wheezing attributable to atopy (housedust mite specific $\operatorname{IgE}$ $>0.3 \mathrm{kU} / \mathrm{l}$ ) was only $35 \%$. Recently, GarciaMarcos and colleagues, ${ }^{16}$ using the ISAAC questionnaire in Spanish schoolchildren, showed that $62 \%$ of children with current wheezing had atopy.

In developing countries, atopy would not be an important determinant of asthma symptoms or BHR in children, ${ }^{17}{ }^{18}$ even when some of them are within the countries with the highest prevalence of asthma symptoms in the world. ${ }^{19}$ The latter suggests that mechanisms different to atopy may be responsible for asthma symptoms and BHR in children from underprivileged areas, and perhaps for the worldwide variability reported in the prevalence of asthma, atopy and BHR. ${ }^{12}{ }^{13-15}$ It is likely that environmental exposures, different in nature and magnitude, could determine the important variation reported in the prevalence and severity of asthma symptoms globally, and also its relationship with BHR and atopy.

The purpose of our study was to evaluate the relationships between self-reported symptoms of 
asthma, pulmonary function, airway responsiveness and atopy in children living in a low socioeconomic neighbourhood in Santiago, Chile.

\section{METHODS}

From the 3051 schoolchildren (13-14 years old) who participated in the official ISAAC phase I study at our institution, ${ }^{1}$ we randomly selected 100 children who had responded "Yes" to the question "Have you had wheezing in the past 12 months?" (current wheezing group) and 100 children who responded "No" to that question (without current wheezing group). Parents were asked to provide information on the following: history of asthma in their first degree relatives, active tobacco smoking, environmental exposure to tobacco smoke and to other indoor pollutants at home (type of heating and cooking), pets at home (cats, dogs), type of floor covering and carpets at home, and paved streets in their neighbourhood.

Children were from a low income neighbourhood in Santiago (ie, monthly income per home approximately US\$613; 25\% of the population on the poverty line, mean parental educational level 8 or less school years and high atmospheric pollution (PM10 exceeding $400 \mu \mathrm{g} / \mathrm{m}^{3}$ several times during the autumn and winter)).

Each subject was evaluated with spirometry, methacholine bronchial challenge and allergen skin prick test. Tests were performed in random sequences on three consecutive days. Children were studied only when they were free of respiratory symptoms for at least 4 weeks. Those subjects using asthma medication were instructed to discontinue inhaled salbutamol for $12 \mathrm{~h}$ prior to testing and inhaled corticosteroids were continued. None of the subjects was using oral corticosteroids, antihistamines or theophylline.

Lung function (spirometry) was performed using a heated Fleisch type pneumotachograph (model 3810; Hans Rudolph inc. KC, Missouri, USA) with the Medgraphics CPF-S processing system (Medical Graphics Corp.; St Paul, Minnesota, USA). Subjects performed all manoeuvres in the standing position and using a nasal clip. At least three technically acceptable curves were obtained. Values for forced vital capacity (FVC) and forced expiratory volume in $1 \mathrm{~s}\left(\mathrm{FEV}_{1}\right)$ did not differ from the next lowest values by more than $5 \%$ or $100 \mathrm{ml}$, whichever was greater. Reported values were obtained from the best curve with the highest sum of $\mathrm{FEV}_{1}$ and FVC.

Methacholine bronchial challenge was performed if $\mathrm{FEV}_{1}$ was $\geqslant 80 \%$ of the predicted value using the modified Cockcroft's method. Methacholine chloride (ICN Biomedical Inc., Ohio, USA) solution in normal saline was stored at $4{ }^{\circ} \mathrm{C}$ and nebulised at room temperature using a Hudson 1730 jet nebuliser with a fill volume of $2 \mathrm{ml}$. The nebuliser, which was driven by air at a pressure of $344 \mathrm{kPa}(50 \mathrm{psi}$ ) and flow of $6 \mathrm{l} / \mathrm{min}$, had an output of $340-360 \mathrm{mg} / \mathrm{min}$. Subjects inhaled each aerosol through a mouth tube with volume extension piece. Following the initial inhalation of normal saline, a methacholine solution of $0.03 \mathrm{mg} / \mathrm{ml}$ was inhaled by quiet mouth breathing over $2 \mathrm{~min} ; \mathrm{FEV}_{1}$ was obtained 30 and $90 \mathrm{~s}$ after each nebulisation and the lowest value was used for calculations. Doubling concentrations of methacholine were administered every $5 \mathrm{~min}$ until $\mathrm{FEV}_{1}$ decreased by $20 \%$ from the post-saline value or when a concentration of $8 \mathrm{mg} / \mathrm{ml}$ was nebulised. The provocative concentration of methacholine required to decrease $\mathrm{FEV}_{1}$ by $20 \%$ from saline (PC20) was calculated by linear interpolation of logarithmically transformed concentrations. For the purposes of the study, BHR to methacholine was defined as PC20 <8 mg/ml.
The skin prick test to eight common inhalant allergens was performed on the forearm, as well as a positive (histamine) and a negative (solvent) control. The following allergens were employed: Dermatophagoides pteronyssinus, Dermatophagoides farinae, cat, dog, alternaria, grass mixture, trees mixture and weeds mixture (Nelco Laboratories, New York, USA). Atopy was defined as a positive reaction (wheal size measuring $3 \mathrm{~mm}$ or more after subtraction of the control value) to one or more allergens.

The hospital ethics committee approved the study and full informed and signed consent was obtained from all parents.

\section{Statistical analysis}

Statistical analysis for differences between the two groups (current wheezing or without current wheezing) was performed using Fisher and $\chi^{2}$ tests for categorical variables and the Student $t$ test for continuous variables. Multivariate logistic regression was performed using current wheezing as a dependent variable; those factors that were statistically significant $(p<0.05)$ in the univariate analysis were used as independent variables.

The proportion of current wheezing cases "attributable" to BHR to methacholine was estimated by the "population attributable risk" according to Pearce and colleagues. ${ }^{14}$ If exposure has an odds ratio (OR) for current wheezing of $\mathrm{R}$, then the proportion of exposed cases attributable to exposure was expressed as $(R-1) / R$, and the proportion of all cases in the population attributable to exposure (population attributable risk) was $\mathrm{P}(\mathrm{R}-1) / \mathrm{R}$, where $\mathrm{P}$ is the proportion of all exposed cases.

\section{RESULTS}

Ninety-five of 100 adolescents (64 girls) in the current wheezing group and 97 of 100 adolescents (51 girls) in the group without wheezing completed all evaluations (spirometry, methacholine bronchial challenge and skin prick test). The main reason for failure in study completion among the eight adolescents were: family moved out of the city (two in the group with current wheezing and one in the group without wheezing) and unwilling to continue with the evaluation (three in the group with current wheezing and two in the group without wheezing).

Mean (SD) age in adolescents with current wheezing and without wheezing was similar (14.53 (0.57) vs 14.71 (0.61) years) and mean height in the two groups was 160.6 $(7.49) \mathrm{cm}$ and $162.4(7.39) \mathrm{cm}$, respectively. There were significantly less males in the group with current wheezing compared with the group without wheezing (32.6 vs $47.4 \%$; $\mathrm{p}=0.037$ ). Adolescents with current wheezing had a higher prevalence of maternal asthma and siblings with asthma than those without wheezing $(19.2 \%$ vs $6.2 \%(p=0.007)$ and $18.3 \%$ vs $7.2 \%(p=0.02)$, respectively) (table 1$)$. The prevalence of active tobacco consumption (in the past 12 months) and intradomiciliary tobacco exposure was similar between those with and without current wheezing $(32.6 \%$ vs $33.0 \%$ and $68.4 \%$ vs $66 \%$, respectively). Also, the prevalence of exposure to different fuels used for cooking or heating (gas, kerosene and wood), the proportion of carpets and types of floor covering at home and paved streets were similar between adolescents with and without current wheezing (table 1).

There was no significant difference in the proportion of positive skin tests between those children who reported wheezing in the past 12 months compared with those who 
Table 1 Demographic and environmental characteristics of adolescents with and without self-reported current wheezing

\begin{tabular}{llcc}
\hline & $\begin{array}{c}\text { Current wheezing } \\
(\mathbf{n = 9 5 )}\end{array}$ & $\begin{array}{l}\text { Without current } \\
\text { wheezing (n= 97) }\end{array}$ & OR (95\% CI) \\
\hline Gender (\% males) & 32.6 & 47.4 & $1.8(1.0-3.5)$ \\
Maternal asthma (\%)* & 19.2 & 6.2 & $3.6(1.3-11.6)$ \\
Paternal asthma (\%) & 9.7 & 9.3 & $1.1(0.4-3.1)$ \\
Siblings with asthma (\%)* & 18.3 & 7.2 & $2.9(1.1-8.6)$ \\
Tobacco active in last 12 m (\%) & 32.6 & 33.0 & $1.0(0.5-1.9)$ \\
Intradomiciliary tobacco exposure (\%) & 68.4 & 66.0 & $1.1(0.6-2.1)$ \\
Contaminant heating/cooking at home & & & $0.8(0.4-1.5)$ \\
$\quad$ Gas & 27.4 & 33 & $1.3(0.7-2.5)$ \\
Kerosene & 70.5 & 65 & $1.3(0.3-6.7)$ \\
$\quad$ Wood & 8.5 & 5.1 & $1.0(0.5-2.1)$ \\
Animals at home (stray dogs and cats) & 75.8 & 75.3 & $1.6(0.6-4.8)$ \\
Unpaved at home (\%) & 12.6 & 8.3 & $1.2(0.6-2.5)$ \\
\hline
\end{tabular}

${ }^{*} \mathrm{p}<0.05,{ }^{* *} \mathrm{p}<0.01$.

did not (44\% vs 42\%; $p=0.89$, OR 1.1 (95\% confidence interval (CI) 0.6 to 2.0$)$ ) (table 2, fig 1). The prevalence of positive responses to the allergens used was as follows: Dermatophagoides pteronyssinus (26.6\%), Dermatophagoides farinae (20.3\%), grass mixture $(16.2 \%)$, cat $(9.4 \%), \operatorname{dog}(8.9 \%)$, weeds mixture $(8.3 \%)$, alternaria $(7.3 \%)$ and trees mixture $(5.2 \%)$. The reported proportion of pets at home (mainly stray dogs and to a lesser extent cats) was $76 \%$ in current wheezing children and $75 \%$ in those without wheezing. The proportion of positive skin reactions to dog and cat was not significantly different between the groups ( $8.4 \%$ vs $9.3 \%$ and $12.6 \%$ vs $6.2 \%$, respectively).

The baseline values of FVC and $\mathrm{FEV}_{1}$ were similar between children with and without current wheezing (FVC 114.78 (12.1) vs $115.9(12.7)$, respectively $(p=0.50)$ and $\mathrm{FEV}_{1} 116.72$ (12.3) vs 120.28 (14.5) ( $p=0.07)$, respectively), as well as $\mathrm{FEV}_{1} / \mathrm{FCV}(89.2$ $(5.3) \%$ vs $90.3(5.5) \%$, respectively; $p=0.15)$ (table 2 ).

The group with current wheezing had a significantly larger proportion of adolescents with BHR to methacholine than the group without current wheezing $(71.5 \%$ and $52.6 \%$, respectively, $p=0.007$, OR 2.3 (95\% CI 1.2 to 4.3$)$ ) (table 2$)$. The proportion of current wheezing cases "attributable" to BHR to methacholine was 40\%.

Among males, the proportion with BHR to methacholine was significantly larger in the group with current wheezing compared with those without current wheezing $(77 \%$ vs $52 \%$, $p=0.028$, OR 3.1 (95\% CI 1 to 10.3)). Regarding females, the proportion with BHR was also larger in the group with current wheezing but this was not significant (69\% vs $53 \%, p=0.083$, OR 2.0 ( $95 \%$ CI 0.9 to 4.5$)$ ) (fig 1). The prevalence of a positive skin test was similar in both groups (table 2), and when stratified by gender, no significant difference in the proportion

Table 2 Pulmonary function and methacholine bronchial challenge in adolescents with and without self-reported current wheezing

\begin{tabular}{lll}
\hline & $\begin{array}{l}\text { Current wheezing } \\
(\mathbf{n}=\mathbf{9 5})\end{array}$ & $\begin{array}{l}\text { Without current } \\
\text { wheezing (n=97) }\end{array}$ \\
\hline Baseline FVC (\%predicted) & $114.8(12.1)$ & $116.0(12.7)$ \\
Baseline FEV 1 (\%predicted) & $116.7(12.3)$ & $120.3(14.5)$ \\
Baseline $\mathrm{FEV}_{1} / \mathrm{FVC}(\%$ predicted) & $89.2(5.3)$ & $90.3(5.5)$ \\
PC20 $<8 \mathrm{mg} / \mathrm{ml}(\%)^{* *}$ & 71.6 & 52.6 \\
Positive skin test $\%)$ & 44.2 & 42.3
\end{tabular}

** $\mathrm{p}<0.01$.

$\mathrm{FEV}_{1}$, forced expiratory volume in $1 \mathrm{~s}$; FVC, forced vital capacity; PC20, provocative concentration of methacholine required to decrease $\mathrm{FEV}_{1}$ by $20 \%$ from saline. of positive skin tests was found between children with and without current wheezing (males: $52 \%$ and $41 \%$, respectively, $\mathrm{p}=0.3$, OR $1.5(95 \%$ CI 0.5 to 4.2$)$; females: $41 \%$ and $43 \%$, respectively, $p=0.07$, OR 0.9 (95\% CI 0.4 to 2.0)) (fig 1 ). Atopic adolescents with current wheezing had significantly more BHR to methacholine than non-atopics (negative skin test) $(83.3 \%$ vs $62.3 \%, p=0.024$, OR 3.0 (95\% CI 1.0 to 9.5)). When the groups were stratified by gender, atopic males had slightly more BHR to methacholine than non-atopics $(71.4 \%$ vs $54.8 \%, p=0.13$, OR 2.1 (95\% CI 0.7 to 6.0)) and atopic females had significantly more BHR to methacholine than non-atopics $(72.9 \%$ vs $53.7 \%$, $\mathrm{p}=0.04$, OR 2.3 (95\% CI 1.0 to 5.6$)$ ).

The result of the multiple logistic regression analysis showed that BHR (adjusted OR 2.02 (95\% CI 1.1 to 3.7); $p=0.02$ ) and maternal asthma (adjusted OR 3.1 (95\% CI 1.2 to 8.3); $p=0.03$ ) were the only risk factors that remained significantly and independently associated with current wheezing.

\section{DISCUSSION}

This study shows that adolescents from an underprivileged urban area who reported wheezing in the past 12 months had significantly more BHR to methacholine than those who did not have current wheezing, and this was not associated with

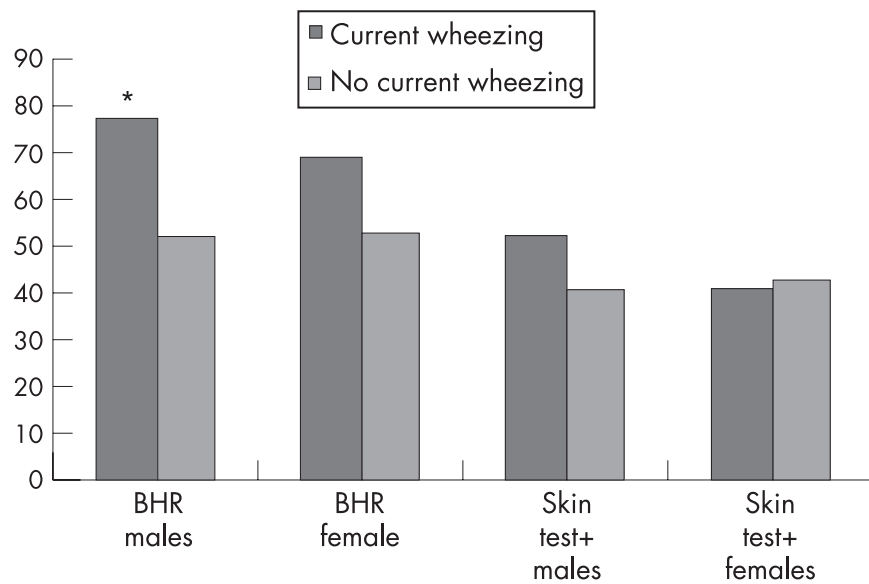

Figure 1 Proportion of adolescents with and without current wheezing who had bronchial hyperresponsiveness (BHR) to methacholine and positive skin prick test by gender. ${ }^{*} p=0.28$ between the current wheezing and the no current wheezing groups. 
atopy. Seventy-one per cent of children with current wheezing had BHR to methacholine and only 44\% had atopy; a very similar proportion of atopy (42.3\%) was found in those children without current wheezing but in this group the proportion of BHR was $53 \%$.

The prevalence of atopy in children with current asthma symptoms from developed countries is relatively similar (ie, $62.4 \%$ in Spain, ${ }^{16} 58 \%$ in Sweden ${ }^{18}$ and $69 \%$ in western Germany). ${ }^{20}$ However, in developing countries, the prevalence of atopy has a considerable variability, from $21.5 \%$ in $\mathrm{Peru}^{17}$ and $26 \%$ in Estonia ${ }^{18}$ to $89 \%$ in Costa Rica. ${ }^{21}$ In those children without current asthma symptoms, the prevalence of atopy also varies and the reported figures are $28.7 \%$ in Spain, $31.4 \%$ in Peru, 22\% in Sweden, 9\% in Estonia and 65.5\% in Costa Rica. ${ }^{16-18} 21$ This wide variability in the proportion of atopy observed in adolescents with current wheezing (ranging from $21.5 \%$ to $89 \%$ ) and also in those without current wheezing (ranging from 9\% to 65.5\%) would support the idea that atopy may be just a parallel event in the pathogenesis of asthma. ${ }^{13}$ Furthermore, overestimation of atopy as causative of asthma may have delayed the research on other important possible aetiological mechanisms for the development of the disease, ${ }^{14}$ such as those that eventually determined asthma symptoms in our non-atopic children and possibly in other individuals from underprivileged populations.

The similarly low proportion of atopy in children with or without current asthma symptoms found in the present study is in agreement with other studies from Peru and Estonia, where current asthma symptoms were not related to atopy, decreased pulmonary function or BHR. ${ }^{17}{ }^{18}$ In contrast, a study from Costa Rica (ISAAC phase II) found that atopy and maternal history of asthma were both associated with an increased risk of current wheezing but it is worth mentioning that in the same study the proportion of atopy in children without current wheezing was $65.5 \%{ }^{21}$ Furthermore, the high prevalence of current asthma symptoms found in children from Costa Rica (24\%) and Peru $(26 \%)$ in which there was a remarkable difference in the prevalence of atopy (21\% in Peru and $89 \%$ in Costa Rica) suggests that other factors unrelated to atopy (probably characteristic environmental factors present at each locality, different in nature and magnitude) are perhaps more important as determinants of asthma symptoms or BHR and of the differences reported in the literature.

Socioeconomic risk factors seem to be related to asthma symptoms, even in developed countries. For example, in a study from the UK, ${ }^{15}$ the prevalence of wheezing was related to lower social class only in non-atopic individuals. Recently, in Sweden, it has been reported that asthma, rhinitis and allergic sensitisation are more common in lower than in higher socioeconomic groups and this could be related to lifestyle and environmental exposures. ${ }^{22}$ It is likely that environmental risk factors, including those related to low social economic status, may play an important role in the variability of symptoms, BHR and atopy in childhood.

The variability in the prevalence of BHR seems to be independent of the type of challenge methods used, atopy, socioeconomic or development status, and asthma symptoms. For example, the proportion of children without wheezing that had BHR to hypertonic saline found using the same ISAAC phase II protocol was 3\% in Estonia, 30\% in Sweden and 40\% in Costa Rica ${ }^{18}{ }^{21}$; the same significant variability in BHR observed in children from different localities has also been described in adults. ${ }^{2}$ At present, the reasons for the reported variability in the prevalence of asthma symptoms, BHR and atopy are unknown.
Although apparently not related to the prevalence of current asthma symptoms, atopy seems to be an important determinant in the variability of the reported BHR prevalence. In Swedish children, BHR was present in $52 \%$ of atopic wheezing children and in $26 \%$ of those who were non-atopic who reported current wheezing, while in Estonia, BHR was found in $30 \%$ of atopic and $6 \%$ of non-atopic wheezing children ${ }^{18}$; in the present study, the proportions were $83.3 \%$ and $62.3 \%$, respectively. Hence, more important than the difference found in the proportion of BHR between children with and without current wheezing $(71.6 \%$ and $52.6 \%$, respectively) is perhaps the magnitude of the difference (demonstrated by the fact that the population attributable risk of BHR as a "cause" of current wheezing was no more than 40\%). The latter suggests that other mechanisms, independent of atopy and BHR, can induce asthma symptoms in children.

Another finding of this study was the large proportion of children, with and without current wheezing, who were exposed to well known airway irritant factors (eg, indoor kerosene and gas combustion, exposure to tobacco smoke and probably to endotoxin, due to the high proportion of children living with stray dogs and cats as "pets"). In the neighbourhood where the study was performed, PM10 exceeded $400 \mu \mathrm{g} / \mathrm{m}^{3}$ several times during the autumn and winter. Environmental pollution exposure is an important and frequently present nonallergic factor capable of causing asthma symptoms and lung function decline in otherwise non-asthmatic children or increasing asthma symptom severity. ${ }^{23-26}$ It is likely that the high proportion of children without current wheezing who had BHR to methacholine $(52.6 \%)$ in our study could be, at least in part, explained by the longstanding exposure to the above mentioned indoor and outdoor atmospheric pollutants.

This study suggests that under special living conditions (ie, burden of environmental harmful factors, mainly related to low socioeconomics status-smog, indoor pollution, infections), the prevalence of asthma symptoms and BHR to methacholine although high, remains independent from atopy. The latter is in agreement with recent publications suggesting that asthma is not simply the result of a polarised Th2 response ${ }^{13}$; other nonallergic mechanisms, perhaps more important and present early in life, are involved as causative events, ${ }^{13}$ particularly those related to environmental conditions. ${ }^{27}$ It has been demonstrated that viral induced changes in cytokine responses can lead to recurrent wheezing and physician diagnosed asthma in infants. ${ }^{28}{ }^{29}$ In a birth cohort study undertaken in the same city area where the present study was done, the prevalence of recurrent wheezing (three or more episodes) during the first year of life was $40.3 \%$ and was unrelated to personal or familiar atopy. ${ }^{30}$ Considering all of the above, it is likely that early respiratory exposure from birth to an "aggressive environment" (ie, chemicals (smog and gases) and biomass combustion, biological (respiratory virus)), as occurred with the children in this study, may result in modifications of innate inflammatory responses early in life, ${ }^{29} 31$ which could result in the observed different relationship between bronchial responsiveness, atopy and symptomatic expression of disease. Although the long term effects on the respiratory health of children who are continuously exposed to harmful environmental factors and having asymptomatic BHR are unknown, we speculate that the additive effect of both conditions might contribute to increase the population at risk for chronic obstructive pulmonary disease later in adulthood.

The higher prevalence of adolescent females with current wheezing in our study is concordant with previous studies using 
the ISAAC protocol and shows that after puberty, girls had a higher prevalence of current asthma after adjusted for by confounders. $^{32}$ The latter is consistent with our finding in ISAAC phase I in Santiago (unpublished data by the authors), where in girls, the prevalence of current wheezing was higher than boys (64.6\% vs $35.4 \%$, respectively). In the random sample of children 13-14 years old who participated in ISAAC phase I in Santiago, the proportion of females was $53.2 \%$.

In conclusion, this study demonstrated that self-reported symptoms of current asthma correlated well with BHR to methacholine but not with atopy, suggesting that BHR and atopy may have different effects in wheezing symptoms. Furthermore, the similar proportion of atopy and high proportion of BHR found in those children without current asthmatic symptoms suggests a different relationship between symptoms, $\mathrm{BHR}$ and atopy in underprivileged populations exposed since birth to an aggressive environment.

Funding: Grant No 029991CQ: Department of Research and Technology (DICYT), University of Santiago de Chile (USACH).

Competing interests: None.

Ethics approval: yes.

\section{REFERENCES}

1. ISAAC Steering Committee. World-wide variations in the prevalence of asthma symptoms: the International Study of Asthma and Allergies in Childhood (ISAAC). Eur Respir J 1998;12:315-35.

2. Chinn S, Burney $P$, Jarvis $D$, et al. Variation in bronchial responsiveness in the European Community Respiratory Health Survey (ECRHS). Eur Respir J 1997:10:2495-501.

3. Witt C, Stuckey MS, Woolcock AJ, et al. Positive allergy prick tests associated with bronchial histamine responsiveness in an unselected population. J Allergy Clin Immunol 1986:77:698-702.

4. Clifford RD, Howell JB, Radford M, et al. Associations between respiratory symptoms, bronchial response to methacholine, and atopy in two age groups of schoolchildren. Arch Dis Child 1989;64:1133-9.

5. Backer V, Ulrik CS, Hansen KK, et al. Atopy and bronchial responsiveness in random population sample of 527 children and adolescents. Ann Allergy 1992;69:116-22.

6. Roorda RJ, Gerritsen J, van Aalderen WM, et al. Skin reactivity and eosinophil count in relation to the outcome of childhood asthma. Eur Respir J 1993;6:509-16.

7. Droste $\mathbf{J H}$, Wieringa $\mathbf{M H}$, Weyler JJ, et al. Lung function measures and their relationship to respiratory symptoms in 7- and 8-year-old children. Pediatr Pulmonol 1999;27:260-6.

8. Ulrik CS, Backer V. Markers of impaired growth of pulmonary function in children and adolescents. Am J Respir Crit Care Med 1999;160:40-4.

9. Warner J0. Bronchial hyperresponsiveness, atopy, airway inflammation, and asthma. Pediatr Allergy Immunol 1998;9:56-60.

10. Withers NJ, Low L, Holgate ST, et al. The natural history of respiratory symptoms in a cohort of adolescents. Am J Respir Crit Care Med 1998:158:352-7.

11. Sears MR, Burrows B, Flannery EM, et al. Relation between airway responsiveness and serum IgE in children with asthma and in apparently normal children. N Eng/ J Med 1991:325:1067-71.
12. Clifford RD, Pugsley A, Radford M, et al. Symptoms, atopy, and bronchial response to methacholine in parents with asthma and their children. Arch Dis Child 1987:62:66-73

13. Salvi SS, Babu S, Holgate ST. Is asthma really due to a polarized T cell response toward a helper T cell type 2 phenotype? Am J Respir Crit Care Med 2001;164:13436 .

14. Pearce N, Pekkanen J, Beasley R. How much asthma is really attributable to atopy? Thorax 1999;54:268-72.

15. Court CS, Cook DG, Strachan DP. Comparative epidemiology of atopic and non-atopic wheeze and diagnosed asthma in a national sample of English adults. Thorax 2002; 57:951-7.

16. Garcia-Marcos L, Castro-Rodriguez JA, Suarez-Varela MM, et al. A different pattern of risk factors for atopic and non-atopic wheezing in 9-12-year-old children. Pediatr Allergy Immunol 2005;16:471-7.

17. Penny ME, Murad S, Madrid SS, et al. Respiratory symptoms, asthma, exercise test spirometry, and atopy in schoolchildren from a Lima shanty town. Thorax 2001; 56:607-12.

18. Annus T, Bjorksten B, Mai XM, et al. Wheezing in relation to atopy and environmental factors in Estonian and Swedish schoolchildren. Clin Exp Allergy 2001:3:1846-53.

19. Mallol J, Solé D, Asher I, et al. Prevalence of asthma symptoms in Latin America: the International Study of Asthma and Allergies in Childhood (ISAAC). Pediatr Pulmonol 2000;30:439-44.

20. Von Mutius E, Martinez FD, Fritzsch C, et al. Prevalence of asthma and atopy in two areas of West and East Germany. Am J Respir Crit Care Med 1994;149:358-64.

21. Soto-Ouiroz ME, Silverman EK, Hanson LA, et al. Maternal history, sensitization to allergens, and current wheezing, rhinitis, and eczema among children in Costa Rica. Pediatr Pulmonol 2002;33:237-43.

22. Almqvist C, Pershagen G, Wickman M. Low socioeconomic status as a risk factor for asthma, rhinitis and sensitization at 4 years in a birth cohort. Clin Exp Allergy 2005; 35:612-18

23. Gent JF, Triche EW, Holford TR, et al. Association of low-level ozone and fine particles with respiratory symptoms in children with asthma. JAMA 2003;290:185967.

24. Just J, Ségala C, Sahraoui F, et al. Short-term health effects of particulate and photochemical air pollution in asthmatic children. Eur Respir J 2002;20:899-906.

25. McConnell R, Berhane K, Gilliland F, et al. Asthma in exercising children exposed to ozone: a cohort study. Lancet 2002;359:386-91.

26. Horak F Jr, Studnicka M, Gartner C, et al. Particulate matter and lung function growth in children: a 3-yr follow-up study in Austrian schoolchildren. Eur Respir $\mathrm{J}$ 2002;19:838-45.

27. Arshad SH, Kurukulaaratchy RJ, Fenn M, et al. Early life risk factors for current wheeze, asthma, and bronchial hyperresponsiveness at 10 years of age. Chest 2005; 127:502-8

28. Bont L, Heijnen CJ, Kavelaars A et al. Monocyte IL-10 production during respiratory syncytial virus bronchiolitis is associated with recurrent wheezing in a one-year follow-up study. Am J Respir Crit Care Med 2000;161:1518-23.

29. Copenhaver CC, Gern JE, Li Z, et al. Cytokine response patterns, exposure to viruses, and respiratory infections in the first year of life. Am J Respir Crit Care Med 2004;170:175-80.

30. Mallol J, Andrade R, Auger F, et al. Wheezing during the first year of life in infants from low-income population: a descriptive study. Allergol Immunopathol 2005:33:257-63.

31. Guerra S, Lohman IC, Halonen $\mathrm{M}$, et al. Reduced interferon gamma production and soluble CD14 levels in early life predict recurrent wheezing by 1 year of age. Am J Respir Crit Care Med 2004:169:70-6.

32. Fagan JK, Scheff PA, Hryhorczuk D, et al. Prevalence of asthma and other allergic diseases in an adolescent population: association with gender and race. Ann Allergy Asthma Immunol 2001:86:177-84. 